\title{
A high-protein, moderate-energy, regular cheesy snack is energetically compensated in human subjects
}

\author{
Mylène Potier ${ }^{1,2}$, Gilles Fromentin ${ }^{1,3}$, Juliane Calvez ${ }^{1,3}$, Robert Benamouzig ${ }^{4}$, Christine Martin-Rouas ${ }^{5}$, \\ Lisa Pichon $^{2}$, Daniel Tomé ${ }^{1,3}$ and Agnès Marsset-Baglieri ${ }^{1,3 *}$ \\ ${ }^{1}$ INRA, CNRH-IdF, UMR914 Nutrition Physiology and Ingestive Behaviour, F-75005 Paris, France \\ ${ }^{2}$ Armor Protéines, 35460 Saint-Brice en Coglès, France \\ ${ }^{3}$ AgroParisTech, CNRH-IdF, UMR914 Nutrition Physiology and Ingestive Behaviour, F-75005 Paris, France \\ ${ }^{4}$ Department of Gastroenterology, Avicenne Hospital, Assistance Publique-Hôpitaux de Paris, Clinical Investigation Centre of \\ CRNH Ile-de-France (Human Nutrition Research Centre), 93000 Bobigny, France \\ ${ }^{5}$ SB Alliance, Direction de la Stratégie Produits, 78220 Viroflay, France
}

(Received 15 May 2008 - Revised 5 January 2009 - Accepted 6 January 2009 - First published online 16 February 2009)

Snacking is often regarded as a cause of overweight. However, the main issue is to determine whether the consumption of snacks leads to an increase in energy intake or whether a compensation phenomenon exists and maintains daily energy intake at a constant level. The objective of the present study was to determine whether the repeated consumption of a high-protein, moderate-energy, cheesy snack given as a preload $1 \mathrm{~h}$ before a meal altered energy intake at the next meal and then throughout the day, and if this kind of snack was energetically compensated. Normal-weight women $(n$ 27) were recruited for the study. All subjects were healthy non-smokers, aged $18-60$ years. The snacks consisted of portions of cheese containing $22 \mathrm{~g}$ protein, with an energy value of $836 \mathrm{~kJ}$. Two types of snack were compared, differing in terms of the type of milk proteins they contained: the first contained casein only (CAS), while the second contained a mixture of casein and whey proteins (WHEY + CAS; 2:1). The principal finding of the present study was that the ingestion of the two snacks $1 \mathrm{~h}$ before lunch led to energy compensation of 83.1 (SEM 9.4) and 67.0 (SEM 16.4) \% for WHEY + CAS and CAS respectively, at lunch, and 121.6 (SEM 36.5) and 142.1 (SEM 29.7) \% for WHEY + CAS and CAS respectively, regarding the whole-day energy intake. In conclusion, the repeated consumption of a high-protein, moderate-energy, regular cheesy snack should not promote overweight because energy intake appears to be regulated during subsequent meals on the same day.

Satiety: Snacks: Protein: Cheese: Whey

The effect of snacks on energy intake and body weight is still matter of debate. The issue is to determine whether the consumption of snacks leads to an increase in energy intake, meaning that the energy provided by snacks is added to daily energy intake, or if a compensation phenomenon occurs because individuals unconsciously tend to consume less energy during the meal after a snack ${ }^{(1,2)}$. Moreover, in case of compensation, it is interesting to see if it is a full compensation resulting in a constant daily energy intake or a partial compensation, observed when the reduction of energy intake at the test meal is lower than the energy of the snack. Obviously, this effect can be modulated by several factors, including the amount of energy provided by the snack, its nutritional composition and whether the individual is used to consuming snacks or not.

In most studies using a preload paradigm, the energy value of the preload is between 1200 and $3000 \mathrm{~kJ}$; this is relatively high, as it provides more energy than the usual mean energy contribution of snacks ${ }^{(3)}$. Moreover, in nearly all studies, there has been no repeated intake of the preload, and food intake is measured the first time after volunteers eat the preload. As previously suggested, energy compensation after a reduced-fat lunch depends on whether subjects are used to consuming snacks or not. Those who are used to, said to be 'nibblers', compensate more than 'gorgers' who have a low habitual eating frequency ${ }^{(4)}$. Moreover, it has been shown that repeated consumption of the same food over a few days constitutes a learning phase for the effects on appetite of this food, which then determines food intake during the post-training test ${ }^{(5,6)}$. Lastly, the composition of a snack is also important. Of the three macronutrients, protein is thought to have the most marked effect on satiety ${ }^{(7-12)}$. In addition, some authors have reported that satiety can be modulated by protein type ${ }^{(13-15)}$. However, during most studies, the amount of protein used as a preload is dramatically high (about $50 \mathrm{~g}$ ) and taken as pure protein in a liquid form.

The objective of the present study was thus to determine whether the repeated consumption of a high-protein,

Abbreviations: CAS, snack containing casein only; WHEY + CAS, snack containing both whey proteins and casein.

* Corresponding author: Dr Agnès Marsset-Baglieri, fax + 331440818 58, email agnes.marsset-baglieri@agroparistech.fr 
moderate-energy, regular cheesy snack altered energy intake during the next test meal and then throughout the day, and whether there was any compensation for this type of snack. Two high-protein snacks were used, one containing casein only $(22.9 \mathrm{~g})$ and the other containing both casein $(14.5 \mathrm{~g})$ and whey proteins $(7 \cdot 1 \mathrm{~g})$.

\section{Subjects and methods}

The present study was performed at the Human Nutrition Research Centre (Avicenne Hospital, Bobigny, France). The study was approved by the Ethics Committee for Ile de France X (Aulnay-sous-Bois, France).

\section{Subjects}

Twenty-seven women were recruited by means of posters and messages sent to electronic mailing lists. All subjects were healthy non-smokers, aged 18-60 years, with a BMI ranging from 18 to $25 \mathrm{~kg} / \mathrm{m}^{2}$. They had no food allergies or dislikes regarding the foods proposed for the test meals and preloads, and were not taking any medication known to affect appetite. Moreover, we only recruited volunteers who, in response to a general food habits questionnaire, stated that they were used to eating three regular meals per $d$ and did not consume any morning snack on a regular basis. Pregnant or breast-feeding women, athletes in training, individuals with a score $>10$ on the Three-Factor Eating Questionnaire ${ }^{(16)}$ and those suffering from hypercholesterolaemia or diabetes were not included in the study. Because knowledge of the purpose of the present study could impact on the participants' eating behaviour, they were told that its aim was to assess the effect of consuming a snack on their attentiveness and concentration. In support of this, subjects had to complete a short test comprising standard logical questions on each test day, although the results were not analysed. The subjects received financial compensation for their participation, and the true nature of the study was revealed to them during a debriefing session at the end of the study.

\section{Menus and foods}

All foods were widely available, industrial products. Before the study started, we ensured that volunteers liked the different foods proposed, in order to reduce lassitude and dislikes. Subjects were provided with a wide variety of foods to make up a typical French breakfast, biscuits and an apple sauce portion for an optional afternoon snack and a full menu for dinner. Breakfast, the afternoon snack and dinner were provided in packed containers that the volunteers ate freely at home. Lunch was taken at the Research Centre in private cubicles and was a full menu comprising a starter, main course and dessert. All foods (Table 1) were served in generous portions that were weighed before being served and reweighed after the subjects had eaten in order to obtain the net amount consumed of each food. Subjects had to return any uneaten foods from their packed meals the day after each test day.
Table 1. Energy content of food served to the subjects

\begin{tabular}{|c|c|}
\hline & Energy of the portion $(\mathrm{kJ})$ \\
\hline \multicolumn{2}{|l|}{ Breakfast } \\
\hline Semi-skimmed milk & $982 \cdot 3$ \\
\hline Orange juice & 384.6 \\
\hline Bread & $936 \cdot 3$ \\
\hline Cornflakes & $760 \cdot 8$ \\
\hline Jam & $1337 \cdot 8$ \\
\hline Butter & $1320 \cdot 9$ \\
\hline Cocoa powder & 313.5 \\
\hline Powdered sugar & $668 \cdot 8$ \\
\hline Yoghurt & $200 \cdot 6$ \\
\hline \multicolumn{2}{|l|}{ Lunch } \\
\hline \multicolumn{2}{|l|}{ Menu 1} \\
\hline Seasoned grated carrots & $1291 \cdot 6$ \\
\hline Vegetarian pizza & $3026 \cdot 3$ \\
\hline Yoghurt & $200 \cdot 6$ \\
\hline Powdered sugar & $167 \cdot 2$ \\
\hline Apple sauce & 1254 \\
\hline \multicolumn{2}{|l|}{ Menu 2} \\
\hline Seasoned grated celery & $1417 \cdot 0$ \\
\hline Leek and cheese pie & 3762 \\
\hline Yoghurt & $200 \cdot 6$ \\
\hline Caster sugar & $167 \cdot 2$ \\
\hline Pear sauce & $1153 \cdot 7$ \\
\hline \multicolumn{2}{|l|}{ Afternoon snack } \\
\hline Chocolate biscuits & 928.0 \\
\hline Apple sauce & 221.5 \\
\hline \multicolumn{2}{|l|}{ Dinner } \\
\hline \multicolumn{2}{|l|}{ Menu 1} \\
\hline Seasoned semolina mixed salad & $2470 \cdot 4$ \\
\hline Salmon and pasta dish & $1860 \cdot 1$ \\
\hline Cheese & $1801 \cdot 6$ \\
\hline Vanilla cream & $1580 \cdot 0$ \\
\hline \multicolumn{2}{|l|}{ Menu 2} \\
\hline Seasoned rice mixed salad & $1680 \cdot 4$ \\
\hline Beef and potato dish & $2487 \cdot 1$ \\
\hline Cheese & $1801 \cdot 6$ \\
\hline Chocolate cream & $1555 \cdot 0$ \\
\hline
\end{tabular}

\section{Preloads}

Two types of preloads were used, both taking the form of a $75 \mathrm{~g}$ high-protein cheese portion (Table 2). The first (CAS) was a portion of commercially available French cheese and only contained casein as protein; the second (WHEY + CAS) was a portion of cheese specially manufactured for the study in which one-third of the casein was replaced by whey

Table 2. Protein, lipid, carbohydrate and energy content of the preloads

\begin{tabular}{lcc}
\hline & WHEY + CAS & CAS \\
\hline Energy density (kJ/100 g) & 1014 & 1116 \\
Weight of a portion (g) & $75 \cdot 0$ & $75 \cdot 0$ \\
Energy content per portion (kJ) & 752 & 836 \\
Proteins per portion (g) & $22.9^{\star}$ & 21.6 \\
Proteins per portion (E\%) & $50 \cdot 4$ & 43.2 \\
Lipids per portion (g) & $9 \cdot 2$ & 12.0 \\
Lipids per portion (E\%) & 45.5 & 53.9 \\
Carbohydrates per portion (g) & 1.9 & 1.5 \\
Carbohydrates per portion (E\%) & 4.2 & 3.0
\end{tabular}

WHEY + CAS, snack containing both whey proteins and casein; CAS, snack containing casein only; $E \%$, percentage of energy provided by one macronutrient.

* Including $7.1 \mathrm{~g}$ whey proteins. 
proteins. The two preloads were isovolumic, contained the same quantity of proteins ( $22 \mathrm{~g})$ and were almost isoenergetic: 836 and $752 \mathrm{~kJ}$ for CAS and WHEY + CAS, respectively, i.e. 1116 and $1014 \mathrm{~kJ} / 100 \mathrm{~g}$, respectively.

\section{Design}

Each subject participated in two identical randomised sessions, one session per type of preload, resulting in a withinsubject, repeated-measures design. Sessions started with two consecutive test days during which the $24 \mathrm{~h}$ energy intake was measured without consumption of a preload (control). This $2 \mathrm{~d}$ test period was designed to prevent any bias due to the fact that volunteers could be disturbed by visiting the unfamiliar environment of the laboratory, at least during the first session. During the next $5 \mathrm{~d}$, the volunteers were asked to consume at home, at 11.30 hours, a portion of one of the two preloads. These days constituted the training period. Finally, the session ended with two identical consecutive days during which their $24 \mathrm{~h}$ energy intake was measured, this time after consumption at 11.30 hours of the preload given during the training period. In order to minimise lassitude, the menu at lunch and dinner for the two consecutive days was equivalent, but not the same. However, food for breakfast and afternoon snack were always identical. Menu 1 was given on day 1 and menu 2 on day 2 (Table 1). The two sessions were separated by a $5 \mathrm{~d}$ wash-out period (Fig. 1).

On each test day, subjects were instructed to eat the breakfast provided at their home between 07.00 and 08.30 hours, and were not allowed to consume any foods or energy-containing beverages until 11.30 hours. They arrived at the laboratory just before 11.30 hours and were taken to a private cubicle. At 11.30 hours, except on the control day, they were asked to eat the entire preload within $15 \mathrm{~min}$. Between 12.00 and 12.15 hours, they completed the logic and comprehension test. The ad libitum lunch was served at 12.30 hours and the subjects were asked to eat it within $45 \mathrm{~min}$. The volunteers then left the laboratory with the food for their afternoon snack and dinner. They were not allowed to consume any energy-containing beverages for the rest of the day.

\section{Visual analogue scales}

Subjects were required to score their feelings of hunger and fullness, prospective food consumption, their desire to eat and nausea on $100 \mathrm{~mm}$ visual analogue scales. These were completed after breakfast, at 11.30 hours during the control day or immediately before and after consumption of the preload, before and after lunch, at 14.00, 15.00, 17.00 and 19.00 hours and before and after dinner. The palatability of meals (lunch and dinner) and preloads were also measured using visual analogue scales.

\section{Statistical analyses}

Statistical analyses were performed using SAS for Windows (version 9.1; SAS Institute, Inc., Cary, NC, USA). Descriptive data are presented as mean values with their standard errors. One-way ANOVA was performed using the general linear model procedure. Tukey's significant difference test was used for post hoc comparisons of significant effects. Results were considered to be significant at the $P<0.05$ level.

Energy intake from lunch, and the $24 \mathrm{~h}$ food intake with and without the preload were analysed. The percentage of energy compensation at lunch was calculated by dividing the difference in energy intake at lunch between the control situation and situation $\mathrm{X}$ by the energy value of the preload $\mathrm{X}$ :

$$
\begin{aligned}
& \text { Compensation at lunch }=(\text { energy consumed at control lunch } \\
& - \text { energy consumed at lunch after preload X)/ } \\
& \text { energy of preload X. }
\end{aligned}
$$

In the same way, the percentage of energy compensation over the whole day was calculated by dividing the difference in $24 \mathrm{~h}$ energy intake between the control situation and situation $\mathrm{X}$ by the energy value of the preload $\mathrm{X}$ :

(a) If compensation is statistically $<0 \%$, then compensation is null.

(b) If compensation is statistically $>0 \%$ and statistically $<100 \%$, this constitutes partial compensation.

(c) If compensation is statistically $>0 \%$ and does not differ from $100 \%$, this constitutes complete or full compensation.

(d) If compensation is statistically $>100 \%$, this constitutes overcompensation.

\section{Results}

Subjects

Of the twenty-seven subjects recruited, seven did not complete the protocol (preloads not entirely consumed, problem of compliance with the schedules). As a consequence, the final sample consisted of twenty lean women with a mean BMI of 21.6 (SEM 1.7) $\mathrm{kg} / \mathrm{m}^{2}$ and a mean age of 32.4 (SEM 11.40) years. The debriefing discussion revealed that the volunteers thought that the logic tests were real and had not realised that the purpose of the study was food consumption and the effects of snacks on appetite.

\section{Energy intake}

Within a particular session, energy intake at lunch and throughout the day on the two consecutive control days showed no difference between the two days. The same applied

\begin{tabular}{|c|c|c|c|c|c|c|}
\hline 㘳 & & 証 & & 18 & & 言 \\
\hline Control & Training period & Test & \multirow[b]{2}{*}{ Wash-out } & Control & Training period & Test \\
\hline & Session 1 & & & \multicolumn{3}{|c|}{ Session? } \\
\hline
\end{tabular}
for energy intake on the two consecutive days with the consumption of a snack. Thus the results shown below are the

Fig. 1. Experimental design followed by each subject. (网), Menu 1; (司), menu 2. 
mean values over the two consecutive days in each case. Moreover, there was no session effect, so the control condition is represented by the mean of all four control days during the two sessions. Energy intake at lunch was significantly lower with the WHEY + CAS (2278.1 (SEM 148.4) kJ) and CAS $(2350.4$ (SEM 132.5) kJ) preloads than under the control condition (2910.9 (SEM 107.0) kJ) $(P=0.001$ and $P=0.005$ respectively). No difference was observed between the WHEY + CAS and CAS conditions $(P=0.93)$. When the energy value of the preload was added to the energy intake at lunch, the WHEY + CAS (3038.9 (SEM 148.4) kJ) and CAS (3186.4 (SEM 132.5) kJ) conditions did not differ from the control $(P=0.75$ and $P=0.27$ respectively) (Table 3$)$. Energy compensation at lunch with the CAS preload reached 67.0 (SEM 16.4) \%, which constituted partial compensation (statistically $>0 \%$ and statistically $<100 \%$ ). Energy compensation at lunch with the WHEY + CAS preload reached 83.1 (SEM 9.4) \%, which constituted complete compensation since it was statistically $>0 \%$ and did not differ from $100 \%$. There was no significant difference between the energy compensation of the two preloads.

Energy intake during the whole day (energy of the snack not included) after the WHEY + CAS preload (9075.2 (SEM 537.1) kJ), CAS preload (8811.9 (SEM 490.3) kJ) and under control conditions $(10000 \cdot 2$ (SEM 329.8) kJ) did not significantly differ $(P=0.83)$. The total $24 \mathrm{~h}$ energy intake (energy of the snack included) under control conditions did not differ from the WHEY + CAS (9836.0 (SEM 537.1) kJ; $P=0.96)$ or CAS conditions (9647.9 (SEM $490.3 \mathrm{~kJ})$; $P=0.82$ ) (Table 3 ). The whole-day energy compensation with the two preloads was complete (statistically $>0 \%$ and not differing from 100\%): 121.6 (SEM 36.5) \% with the WHEY + CAS preload and 142.1 (SEM 29.7) \% with the CAS preload. There was no significant difference between the whole-day energy compensation of the two preloads.

\section{Palatability of foods and visual analogue scale ratings}

The palatability of the two menus did not differ regarding lunch (49 (SEM 2) $\mathrm{mm}$ for menu 1 and 53 (SEM 2) $\mathrm{mm}$ for menu 2) or dinner (57 (SEM 2) $\mathrm{mm}$ for menu 1 and 55 (SEM 2) $\mathrm{mm}$ for menu 2) and did not vary on the different days of the study. However, the palatability of the CAS preload was judged better than that of the WHEY + CAS preload $(P<0.001$ regarding taste, texture and appearance). Pleasantness scores for taste, texture and appearance were 54 (SEM 2), 52 (SEM 3) and 62 (SEM 2) mm, respectively for CAS and 37 (SEM 3), 40 (SEM 3) and 45 (SEM 2) mm for WHEY + CAS. Under all conditions, no significant differences were found with respect to subjective ratings of hunger, fullness, nausea, prospective food consumption or desire to eat at the end of the breakfast or before consuming the preload. Immediately after eating the preload (CAS or WHEY + CAS) and before lunch, subjects reported a greater reduction in hunger, desire to eat and prospective food consumption, as well as a greater increase in fullness, when compared with the control condition $(P<0 \cdot 05)$. After lunch and for the rest of the day, no difference was observed between subjective ratings for hunger, fullness, nausea, prospective food consumption and desire to eat under the three conditions (Fig. 2).

\section{Discussion}

The purpose of the present experiment was to determine whether the repeated consumption of a high-protein snack containing a moderate amount of energy and given as a preload could affect energy intake at subsequent meal(s) and was energetically compensated. The principal observation was that consumption of a $836 \mathrm{~kJ}$ preload, where more than $40 \%$ of energy is provided by proteins, $1 \mathrm{~h}$ before an $\mathrm{ad}$ libitum meal resulted in a partial compensation during this meal and in a full compensation concerning the $24 \mathrm{~h}$ energy intake. The originality of our design was the fact that two consecutive days of testing were performed using similar menus for the meals. We observed a good repeatability of energy consumption on the two consecutive days under each condition. This result showed that, in line with the palatability scores, which were identical, our two menus were accepted in a same way and the subjects were not disturbed by eating in an inhabitual environment.

The results of the present study showed that volunteers ate significantly less at lunch after consuming a high-protein preload, but the reduction in energy intake compared with control conditions was less than the energy value of the preload. When we compared the energy consumption of the whole test day (breakfast, lunch, afternoon snack and dinner), we observed that the total energy intake did not differ on days with a preload from that on control days. Consequently, partial compensation was made during the meal following the consumption of snacks and full compensation over the whole day. An energy compensation phenomenon is often observed during experiments using high-protein preloads, but in contrast to the present results, test meal compensation is often greater than that concerning total day intake ${ }^{(12,17,18)}$. For instance, De Graaf \&

Table 3. Energy intake at lunch and over the $24 \mathrm{~h}$ period (kJ) (Mean values with their standard errors for twenty subjects)

\begin{tabular}{|c|c|c|c|c|c|c|}
\hline & \multicolumn{2}{|c|}{ Control } & \multicolumn{2}{|c|}{ WHEY + CAS } & \multicolumn{2}{|c|}{ CAS } \\
\hline & Mean & SEM & Mean & SEM & Mean & SEM \\
\hline Lunch & $2910 \cdot 9^{a}$ & $107 \cdot 0$ & $2278 \cdot 1^{\mathrm{b}}$ & $148 \cdot 4$ & $2350 \cdot 4^{b}$ & 132.5 \\
\hline Preload + lunch & $2910 \cdot 9^{a}$ & $107 \cdot 0$ & $3038.9^{a}$ & $148 \cdot 4$ & $3186 \cdot 4^{a}$ & 132.5 \\
\hline $24 \mathrm{~h}$ intake & $10000 \cdot 2^{\mathrm{a}}$ & $329 \cdot 8$ & $9075 \cdot 2^{\mathrm{a}}$ & $537 \cdot 1$ & $8811.9^{\mathrm{a}}$ & $490 \cdot 3$ \\
\hline $24 \mathrm{~h}$ intake + preload & $10000 \cdot 2^{\mathrm{a}}$ & 329.8 & $9836 \cdot 0^{\mathrm{a}}$ & 537.1 & $9647.9^{a}$ & $490 \cdot 3$ \\
\hline
\end{tabular}

WHEY + CAS, snack containing both whey proteins and casein; CAS, snack containing casein only.

a,b Mean values within a row with unlike superscript letters were significantly different $(P<0.05)$. 


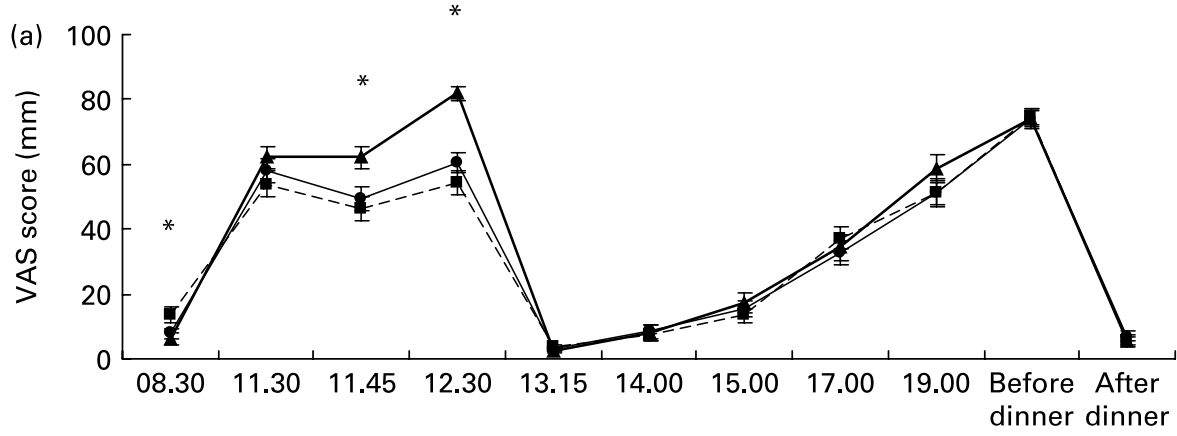

Time of day (hours)

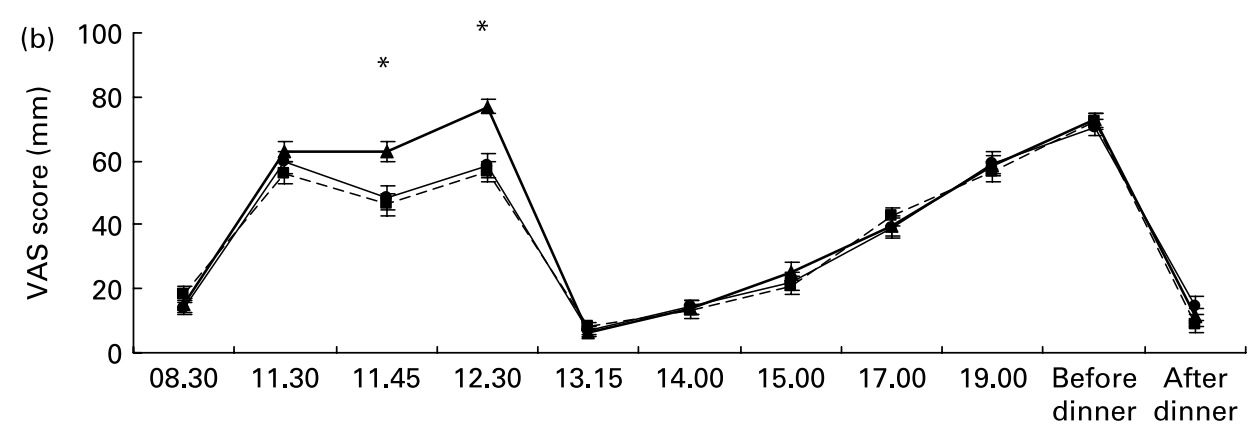

Time of day (hours)

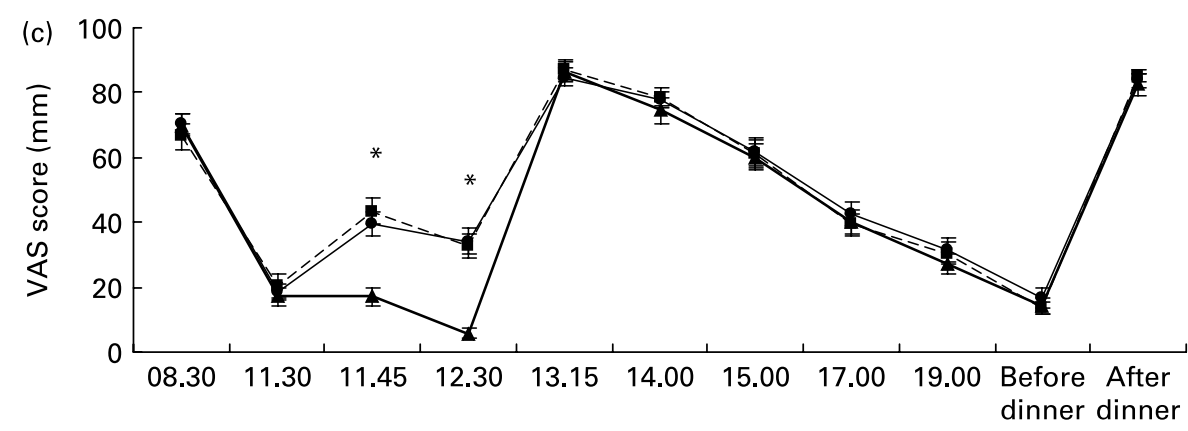

Time of day (hours)

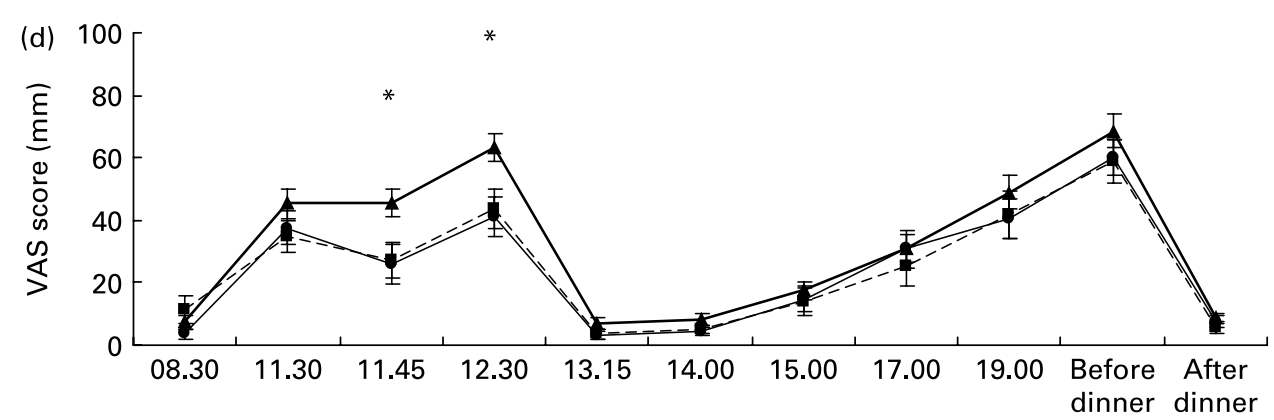

Time of day (hours)

Fig. 2. Hunger (a), prospective food consumption (b), fullness (c) and desire to eat (d) scores throughout the day measured using visual analogue scales (VAS). $(-\boldsymbol{\Delta}-)$, Control (no snack); (--- -), casein snack; (--), whey proteins + casein snack. Values are means, with standard errors represented by vertical bars. ${ }^{*}$ Mean values for both snacks differed from that for the control $(P<0.05)$.

Hulshof $^{(17)}$ showed that a preload of $1 \cdot 3 \mathrm{MJ}$ containing $27 \mathrm{~g}$ milk and soyabean protein consumed $2 \mathrm{~h}$ before a buffet-type lunch resulted in $107 \%$ compensation at lunch and only $8 \%$ in terms of total intake over the day. Such differences could arise from the fact that several parameters could influence the results. The main reason could be the fact that our preloads are solid and not liquid, but the source and quantity of proteins, the amount of energy in the preload, the type of macronutrient 
consumed and the interval elapsing between the preload and the test meal may also interfere. In our case, an interval of $1 \mathrm{~h}$ between the preload and test meal appeared to be appropriate, because some of the studies by Porrini et al. ${ }^{(12)}$ and Anderson et al. ${ }^{(14)}$ demonstrated the satiety effect of a preload on a test meal eaten $0-120 \mathrm{~min}$ after its ingestion. The amount of energy of our preload seems to be sufficient too, since studies of Porrini et al. ${ }^{(12)}$ and Anderson et al. ${ }^{(14)}$ managed to show an effect of preloads of 648 and $833 \mathrm{~kJ}$ respectively. A further explanation is that during most studies, volunteers only ingested each preload once, while we used a protocol involving repeated ingestion $(5 \mathrm{~d})$ of the preload. During the present study, this training period was designed to induce (if it was necessary) a learned response in volunteers to the metabolic consequences on satiety of the ingestion of a high-protein preload. The influence of training would be an interesting question to address but the present study was not designed to look at this.

The digestion and absorption of whey and casein differ in that casein, unlike whey, coagulates in the stomach due to its precipitation by gastric acid ${ }^{(19,20)}$. As a result, overall gastric emptying time for casein is longer and there is a smaller postprandial increase in plasma amino acids compared with the non-coagulating whey protein. The concept of 'fast' and 'slow' proteins was introduced by Boirie et al. ${ }^{(21)}$ to describe these differences in digestion and absorption of whey and casein. It might be predicted therefore that whey, a 'fast' protein, would be more satiating than casein, perhaps on the basis of Mellinkoff's ${ }^{(15,22)}$ original aminostatic concept showing that a larger rise in plasma amino acids would increase satiety and also because of an early effect of whey proteins on satiety hormones $^{(15)}$ and/or neuropeptides.

No difference was observed between the two cheese preload snacks (CAS and WHEY + CAS). Previous studies using higher levels of pure protein $(50 \mathrm{~g})$ given as a liquid preload had reported differences between whey protein and egg protein $^{(14)}$ or whey protein and casein ${ }^{(15)}$. These studies differed from ours in terms of the quantity of protein administered to the volunteers (our snacks contained only $22 \mathrm{~g}$ protein). Moreover, we used solid cheese snacks containing either casein $(22 \mathrm{~g})$ or casein $(16 \mathrm{~g})+$ whey protein $(7 \mathrm{~g})$ and not pure protein in a liquid preload.

With respect to the results of visual analogue scales, we were not able to determine a difference between the two types of preload. Volunteers' responses to the four questions about hunger, fullness, prospective food consumption and desire to eat were consistent with their energy intake: for instance, the volunteers stated that they were hungrier just before lunch in the control situation than on days when they had consumed a preload. During our experiment, recorded visual analogue scale scores for taste, texture and visual appearance of preloads indicated that CAS was more palatable than WHEY + CAS. It was previously demonstrated by Warwick et al. ${ }^{(23)}$ that the palatability of a preload could affect subsequent energy intake; indeed, highly palatable vanilla-flavoured high-fat or high-carbohydrate preloads were shown to lead to a reduction in hunger and an increase in fullness ratings compared with identical but unflavoured preloads. With respect to Warwick's conclusions about higher satiety effect of a palatable preload, the CAS preload should cause a higher reduction in food intake since it was more palatable than the WHEY + CAS preload. In contrast, our initial hypothesis was that the WHEY + CAS preload would lead to a greater reduction in food intake because it contains whey protein (supposedly more satiating $\left.{ }^{(15)}\right)$. We could therefore hypothesise that satiating effects due to differences in palatability might have been counterbalanced by intrinsic satiating properties of proteins used in preload formulas, thus leading to identical satiation effects. However, this explanation remains a subject of discussion since De Graaf et al. ${ }^{(24)}$ showed that palatability exerted a more important effect on satiation than on satiety.

The experiment was made using normal-weight subjects because we wanted to study the effect of snacks in conditions as standardised as possible: healthy subjects, with no problem of weight management, no diabetes and cholesterol. However, it is possible that some individuals, such as those who are overweight or obese, are particularly susceptible to the influence of portion size and thus could react differently in front of an ad libitum meal.

In conclusion, in healthy normal-weight women, the repeated ingestion of a snack containing a moderate level of energy and a high level of milk protein fractions, $1 \mathrm{~h}$ before a test meal, resulted in partial energy compensation at the test meal and in full compensation over $24 \mathrm{~h}$. Moreover, a high-protein, moderate-energy, regular snack would not inevitably promote overweight because energy intake was regulated over the day during the study period.

\section{Acknowledgements}

We can confirm that no conflicts of interest were associated with the present study. The study received funding from INRA, and the companies Armor Protéines SA and SB Alliance. M. P., A. M.-B., G. F. and D. T. designed the study and compiled the manuscript. J. C., R. B., C. M.-R., L. P. and Takashi Mikogami contributed to the design of the study. We would also like to thank Anne Regourd, Pascale Reichl and the staff at Avicenne hospital for their assistance in conduct of the protocol.

\section{References}

1. de Graaf C (2006) Effects of snacks on energy intake: an evolutionary perspective. Appetite 47, 18-23.

2. Rolls BJ, Morris EL \& Roe LS (2002) Portion size of food affects energy intake in normal-weight and overweight men and women. Am J Clin Nutr 76, 1207-1213.

3. Bellisle F, McDevitt R \& Prentice AM (1997) Meal frequency and energy balance. Br J Nutr 77, Suppl. 1, S57-S70.

4. Westerterp-Plantenga MS, Wijckmans-Duysens NA \& ten Hoor F (1994) Food intake in the daily environment after energy-reduced lunch, related to habitual meal frequency. Appetite 22, 173-182.

5. Louis-Sylvestre J, Tournier A, Verger P, et al. (1989) Learned caloric adjustment of human intake. Appetite 12, 95-103.

6. Yeomans MR, Weinberg L \& James S (2005) Effects of palatability and learned satiety on energy density influences on breakfast intake in humans. Physiol Behav 86, 487-499.

7. Barkeling B, Rossner S \& Bjorvell H (1990) Effects of a highprotein meal (meat) and a high-carbohydrate meal (vegetarian) on satiety measured by automated computerized monitoring of subsequent food intake, motivation to eat and food preferences. Int $J$ Obes 14, 743-751. 
8. Poppitt SD, Swann DL, Murgatroyd PR, et al. (1998) Effect of dietary manipulation on substrate flux and energy balance in obese women taking the appetite suppressant dexfenfluramine. Am J Clin Nutr 68, 1012-1021.

9. Gerstein DE, Woodward-Lopez G, Evans AE, et al. (2004) Clarifying concepts about macronutrients' effects on satiation and satiety. J Am Diet Assoc 104, 1151-1153.

10. Fischer K, Colombani PC \& Wenk C (2004) Metabolic and cognitive coefficients in the development of hunger sensations after pure macronutrient ingestion in the morning. Appetite 42, 49-61.

11. Marmonier C, Chapelot D \& Louis-Sylvestre J (2000) Effects of macronutrient content and energy density of snacks consumed in a satiety state on the onset of the next meal. Appetite 34, $161-168$.

12. Porrini M, Santangelo A, Crovetti R, et al. (1997) Weight, protein, fat, and timing of preloads affect food intake. Physiol Behav 62, 563-570.

13. Lang V, Bellisle F, Oppert JM, et al. (1998) Satiating effect of proteins in healthy subjects: a comparison of egg albumin, casein, gelatin, soy protein, pea protein, and wheat gluten. Am J Clin Nutr 67, 1197-1204.

14. Anderson GH, Tecimer SN, Shah D, et al. (2004) Protein source, quantity, and time of consumption determine the effect of proteins on short-term food intake in young men. J Nutr 134, 3011-3015.

15. Hall WL, Millward DJ, Long SJ, et al. (2003) Casein and whey exert different effects on plasma amino acid profiles, gastrointestinal hormone secretion and appetite. Br J Nutr 89, 239-248.
16. Stunkard AJ \& Messick S (1985) The three-factor eating questionnaire to measure dietary restraint, disinhibition and hunger J Psychosom Res 29, 71-83.

17. de Graaf C \& Hulshof T (1996) Effects of weight and energy content of preloads on subsequent appetite and food intake. Appetite 26, 139-151.

18. Vozzo R, Wittert G, Cocchiaro C, et al. (2003) Similar effects of foods high in protein, carbohydrate and fat on subsequent spontaneous food intake in healthy individuals. Appetite $\mathbf{4 0}$ $101-107$

19. Billeaud C, Guillet J \& Sandler B (1990) Gastric emptying in infants with or without gastro-oesophageal reflux according to the type of milk. Eur J Clin Nutr 44, 577-583.

20. Miller MJS, Witherly SA \& Clark DA (1990) Casein: a milk protein with diverse biologic consequences. Proc Natl Acad Sci U S A 195, 143-159.

21. Boirie Y, Dangin M, Gachon P, et al. (1997) Slow and fast dietary proteins differently modulate postprandial protein accretion. Proc Natl Acad Sci U S A 94, 14930-14935.

22. Mellinkoff SM, Frankland M, Boyle D, et al. (1956) Relationship between serum amino acid concentration and fluctuations in appetite. J Appl Physiol 8, 535-538.

23. Warwick ZS, Hall WG, Pappas TN, et al. (1993) Taste and smell sensations enhance the satiating effect of both a highcarbohydrate and a high-fat meal in humans. Physiol Behav 53, 553-563.

24. De Graaf C, De Jong LS \& Lambers AC (1999) Palatability affects satiation but not satiety. Physiol Behav 66, 681-688. 